\title{
$\mathrm{LPC}$ 분석 기법 및 $\mathrm{EM}$ 알고리즘 기반 잡음 환경에 강인한 진동 특징을 이용한 고 신뢰성 유도 전동기 다중 결함 분류
}

\author{
강 명 수*, 장 원 철*, 김 종 면*
}

\section{High-Reliable Classification of Multiple Induction Motor Faults using Robust Vibration Signatures in Noisy Environments based on a LPC Analysis and an EM Algorithm}

\author{
Myeongsu Kang*, Won-Chul Jang * Jong-Myon Kim*
}

\section{요 약}

최근 산업 현장에서 유도 전동기의 사용이 증대되고 있으며, 유도 전동기는 산업 현장에서 중요한 역할을 하고 있다. 따라서 유도 전동기의 결함으로 인한 피해를 최소화하기 위해 유도 전동기의 결함 검출 및 분류 시스템의 개 발이 중요한 문제로 대두되고 있다. 따라서 본 논문에서는 유도전동기의 결함을 조기에 식별하기 위해 선형예측 코 딩 $(\mathrm{LPC})$ 기법과 Expectation Maximization(EM) 알고리즘을 이용하여 각각의 유도 전동기 고장의 스펙트럼 포 락처리 모델을 추정한다. 앞서 두 기법을 사용하여 추정된 고장 유형 모델과 마할라노비스 거리(MD) 기법을 사용 하여 유도전동기의 결합을 분류한다. 또한 제안된 알고리즘 성능을 평가하기 위해 기존에 제안된 진동 신호의 특징 을 이용한 유도 전동기 결함 분류 알고리즘과 분류 정확도 측면에서 성능을 검증하였다. 실험 결과, 제안하는 알고 리즘은 잡음이 없는 환경 및 잡음이 섞인 환경에서도 높은 분류 성능을 보였다.

- Keywords : 유도 전동기, 결함 분류, 선형 예측 코딩 분석, $\mathrm{EM}$ 알고리즘, 마할라노비스 거리

\author{
Abstract \\ The use of induction motors has been recently increasing in a variety of industrial sites, and \\ they play a significant role. This has motivated that many researchers have studied on developing \\ •제1저자 : 강명수 •교신저자 : 김종면 \\ •투고일 : 2013. 11. 11, 심사일 : 2013. 11. 25, 게재확정일 : 2014. 1. 19. \\ * 울산대학교 전기전자컴퓨터공학과(School of Electrical, Eletronics and Computer Engineering, University of Ulsan) \\ ※ 이 논문은 2012 년도 정부(교육부)의 재원으로 한국연구재단의 기초연구사업 지원을 받아 수행된 것임 (NRF-2012R1A1A2043644),
}


fault detection and classification systems of induction motors in order to reduce economical damage caused by their faults. To early identify induction motor faults, this paper effectively estimates spectral envelopes of each induction motor fault by utilizing a linear prediction coding (LPC) analysis technique and an expectation maximization (EM) algorithm. Moreover, this paper classifies induction motor faults into their corresponding categories by calculating Mahalanobis distance using the estimated spectral envelopes and finding the minimum distance. Experimental results show that the proposed approach yields higher classification accuracies than the state-of-the-art conventional approach for both noiseless and noisy environments for identifying the induction motor faults.

- Keywords : Induction motor, Fault classification, LPC Analysis, EM algorithm, Mahalanobis distance

\section{I. 서 론}

유도 전동기는 팬, 송풍기, 펌프, 컨베이어 및 압축기 등 대부분의 산업현장에 사용되는 주요한 동력 공급원이다. 이러
한 대전력 공급에 사용되는 유도 전동기의 결함은 생산 설비 성능 저하와 관련되어 막대한 경제적 손실과 모터의 수리 및 보수비용을 초래하기 때문에 결함을 사전에 방지하고 결함발 생 시 손실을 최소화하기 위한 상태 모니터링(condition monitoring) 시스템에 대한 연구가 활발히 진행되고 있다

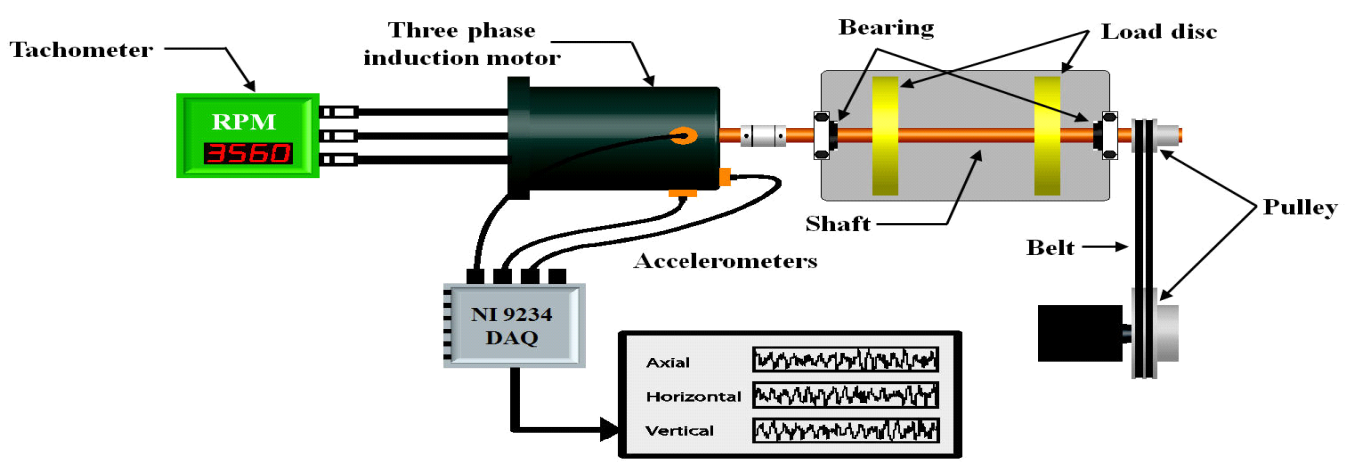

(a)

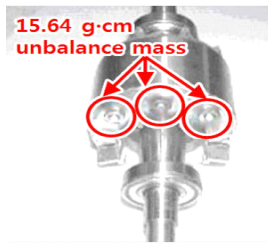

Rotor imbalance

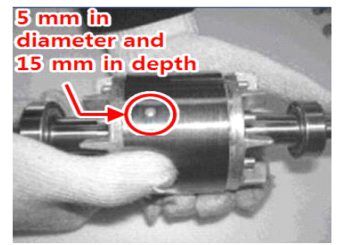

Broken rotor bar

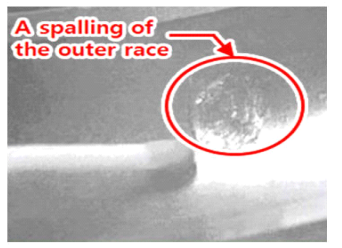

B

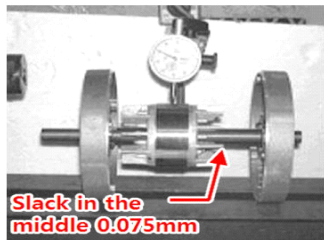

Bowed shaft

그림 1. (a) 유도 전동기 결함 취득 환경, (b) 고장 유도 전동기

Fig. 1. (a) Self-defined test rig for the experimental setup, (b) faulty induction motors 
[1-3].

유도 전동기의 운전 상태를 점검하기 위해 진동 신호가 널 리 이용되는데, 진동 신호에는 유도 전동기와 같은 회전 기계 의 결함 유형별 고유의 특징들이 포함되어 있기 때문이다. 하 지만 진동 신호에 포함된 결함 유형별 특징을 반영하는 파라 미터는 대부분 숨겨져 있으므로 취득한 진동 신호를 결함 검 출 및 분류 시스템에 직접적으로 이용하기에는 어려움이 있 다. 따라서 취득한 진동 신호로부터 결함 유형별 특징을 잘 나타낼 수 있는 특징 벡터를 추출하는 방법은 유도 전동기 결 함 검출 및 분류 시스템에 있어 매우 중요하다[4-6].

최근 유도 전동기의 결함 유형별 분류를 위해서는 신호를 사전에 분석하고, 결함 유형별 특징을 효과적으로 추출하여 분류 알고리즘의 입력으로 사용함으로써 결함을 분류하는 형 태로 연구가 활발히 진행되고 있다. 유도 전동기의 결함 상태 를 효과적으로 표현할 수 있는 특징 추출 기법에는 고속 푸리 에 변환(fast Fourier transform, FFT)을 이용하여 특징 주파수(characteristic frequency)를 추출하는 방법이 주로 사용되어 왔다. 하지만 주파수 스펙트럼의 경우 시간이 지나 면서 유도 전동기 동작 상태가 변하거나 부하의 변동 등으로 인해 특징 주파수 성분의 변동이 발생하므로, 결함 유형별 정 확한 특징 주파수를 추출하는데 어려움이 있다[7-9]. 따라서 본 논문에서는 특징 주파수의 미미한 변동으로 인해 야기되는 유도 전동기의 결함 분류 성능 감소를 줄이기 위해 선형 예측 코딩(linear prediction coding, $\mathrm{LPC}$ ) 분석 및 $\mathrm{EM}$ (expectation maximization) 알고리즘을 이용하여 특 징 주파수 대역의 미미한 변동이 생기더라도 각 결함 유형별 특징을 잘 묘사할 수 있는 스펙트럼 포락선을 추정한다. 이렇 게 추정된 스펙트럼 포락선을 이용하여 각 결함 유형별 강인 한 참조 특징 벡터를 추출하고 이를 바탕으로 알려지지 않은 입력 신호에 대한 특징 벡터와의 마할라노비스 거리 (Mahalanobis distance, MD)를 구함으로써 유도 전동기 의 다중 결함을 분류한다. 또한 제안하는 알고리즘의 성능 평 가를 위해 진동 신호를 이용한 유도 전동기 결함 분류 알고리 즘과 분류 정확도 측면에서 성능을 검증한다[9-11].

본 논문의 구성은 다음과 같다. 2 장에서는 본 논문에서 사 용한 유도 전동기 결함 유형과 각 결함 유형별 진동 신호 취득 환경을 설명한다. 3 장에서는 본 논문에서 제안하는 유도 전동 기의 다중 결함 분류 시스템을 소개하고, 4 장에서는 제안한 알 고리즘의 성능 및 기존 알고리즘과의 성능 비교 결과를 각각 보여준다. 마지막으로 5 장에서 본 논문의 결론을 맺는다.

\section{II. 유도 전동기 결함 유형 및 신호 취득}

본 논문에서는 정상적으로 동작하는 유도 전동기를 포함 일곱 가지 유도 전동기 결함을 취득하기 위한 실험 환경은 그 림 1 (a)와 같으며, 실험에 사용한 유도 전동기는 $0.5 \mathrm{~kW}$, $220 \mathrm{~V}, 3650 \mathrm{RPM}$ (revolutions-per-minute)로 동작한 다. 일곱 가지 결함 유형의 진동 신호 취득을 위해 총 4 개의 유도 전동기를 사용하였으며, 이 중 하나는 정상 상태의 전동 기이다. 먼저 정상 상태의 유도 전동기를 이용하여 정상, 각 정렬 불량, 평형 정렬 불량 및 회전자 불균형 신호를 취득하 였고, 나머지 세 개의 유도 전동기를 통해서는 회전자 봉 파 손 결함, 굽어진 회전자 결함, 베어링 외륜 결함 신호를 각각 취득하였으며 그 결함은 그림 $1(\mathrm{~b})$ 와 같다. 이와 같이 정상 및 일곱 가지 결함에 대해 $8,000 \mathrm{~Hz}$ 로 샘플링된 1 초 길이의 진동 신호 105 개를 축 방향, 수평 방향, 수직 방향으로 유도 전동기에 부착된 가속도 센서로부터 취득하였고, 신호 분석 결과 축 방향의 진동 신호에서 각 결함 유형별 특징을 잘 나 타내었다. 따라서 본 논문에서는 축 방향 진동 신호를 유도 전동기 결함 분류에 사용하며, 표 1 은 유도 전동기 결함 유형 과 그에 대한 간단한 설명이다.

표 1. 유도 전동기의 결함 설명

Table 1. Description of faults of the induction motor

\begin{tabular}{c|c}
\hline \hline Type of fault & Fault description \\
\hline $\begin{array}{c}\text { 각 정렬 불량 } \\
\text { (Angular }\end{array}$ & $\begin{array}{c}\text { 축 지지대를 조절하여 편각 정렬 불량의 } \\
\text { 상태를 가지게 함으로써 얻어진 진동 } \\
\text { 신호 }\end{array}$ \\
\hline $\begin{array}{c}\text { 회전자 봉 균열 (Broken } \\
\text { rotor bar fault, } \\
\text { BRBF) }\end{array}$ & $\begin{array}{c}\text { 34개의 회전자 봉 중에서 12개의 봉을 } \\
\text { 파손하여 얻어진 진동 신호 }\end{array}$ \\
\hline $\begin{array}{c}\text { 정상 } \\
\text { (Normal, NO) }\end{array}$ & 유도 전동기 정상상태 신호 \\
\hline $\begin{array}{c}\text { 회전자 불균형 } \\
\text { (Rotor unbalance } \\
\text { fault, RUF) }\end{array}$ & $\begin{array}{c}\text { 회전자의 추를 달아 무게 불균형을 } \\
\text { 가하여 측정된 진동 신호 }\end{array}$ \\
\hline $\begin{array}{c}\text { 베어링 고장 } \\
\text { (Bearing fault ,BF) }\end{array}$ & $\begin{array}{c}\text { 외륜에 결함을 발생시켜 취득한 진동 } \\
\text { 신호 }\end{array}$ \\
\hline $\begin{array}{c}\text { 굽은 회전축 } \\
\text { (Bowed shaft fault }, \\
\text { BSF) }\end{array}$ & $\begin{array}{c}\text { 최대 0.0075mm로 회전자를 굽혀서 } \\
\text { 측정된 진동 신호 }\end{array}$ \\
\hline $\begin{array}{c}\text { 위상 불 평형 } \\
\text { (Parallel misalignment } \\
\text { fault, PMF) }\end{array}$ & $\begin{array}{c}\text { 축 지지대를 조절하여 편심 정렬 불량의 } \\
\text { 상태를 가지게 함으로써 얻어진 진동 } \\
\text { 신호 }\end{array}$ \\
\hline \hline
\end{tabular}




\section{III. 유도 전동기 결함 분류 시스템}

본 논문에서는 선형 예측 코딩(linear prediction coding, $\mathrm{LPC}$ ) 분석 및 $\mathrm{EM}$ (expectation maximization) 알고리즘 등의 기법을 이용하여 부하 변동 또는 공급되는 입 력 전원으로 인해 동일한 유도 전동기 결함일지라도 그 특징 주파수가 미미하게 변하는데서 기인하는 분류 성능의 저하를 최소화하고자 한다. 또한 유도 전동기 결함 분류를 위해 본 논문에서는 훈련 데이터(training data)로부터 LPC 분석 및 $\mathrm{EM}$ 알고리즘을 통해 유도 전동기 결함 유형별 참조 특징 벡터(reference feature vector)를 생성하고, 참조 특징 벡 터와 테스트 데이터(test data)로부터 추출한 특징 벡터 사 이의 마할라노비스 거리(Mahalanobis distance, $\mathrm{MD}$ )를 구하고 그 거리가 최소가 되는 범주로 결함을 분류한다. 본 논문에서 제안하는 유도 전동기 결함 분류 시스템에서 사용되 는 기법들을 아래에서 소개한다.

\section{1. 선형 예측 코딩(LPC) 분석}

유도 전동기 결함 유형별 스펙트럼 포락선(spectrum envelope)을 나타내기 위해 본 논문에서는 LPC 분석 기법 을 이용한다[12]. LPC는 과거의 인접한 샘플들로부터 현재 의 샘플을 예측하여 신호를 표현하는 방법으로 식(1)과 같이 표현된다.

$$
\hat{x}[n]=\sum_{k=1}^{P} a_{x} x[n-k],
$$

여기서 $a_{x}, \mathrm{k}=1,2,3, \ldots, p$ 는 LPC 계수이고, $p$ 는 선형 예측 계수의 차수이다. 이때 $\mathrm{LPC}$ 를 통해서 나온 LPC 계수 $a_{x}$ 는 입력 신호의 스펙트럼 포락선을 표현하며, 식(2)와 같이 전극 필터(all-pole filter)의 주파수 응답에 의해 정의된다.

$$
H(z)=\frac{1}{1-\sum_{k=1}^{p} a_{k} z^{-k}} .
$$

\section{2. $\mathrm{EM}$ 알고리즘}

$\mathrm{EM}$ 알고리즘은 반복과 정제 과정을 통해 각 객체들이 혼 합 모델(mixture model)에 속할 확률을 조정하여 최적의 모 델을 생성해 나가는 방법이다[13]. $\mathrm{M}$ 차원 데이터 $x=\left\{x_{1}, x_{2}, \ldots, x_{n}\right\}, x_{i} \in R^{M}, i=1,2,3 \ldots, n$ 가 $\mathrm{k}$ 개의 클러 스터 $z=\left\{z_{1}, z_{2}, \ldots, z_{k}\right\}$ 를 가진다고 가정하고, $p_{j}\left(x_{i} \mid \theta_{j}\right), j=1,2, \ldots, k$ 를 파라미터 $\theta_{j}$ 로 표현되는 $\mathrm{j}$ 번째 클 러스터로터 데이터 $x_{i}$ 가 생성될 확률 밀도 함수로 정의하면 혼합 모델(mixture model)에 의한 $x_{i}$ 의 확률 밀도 함수는 식(3)과 같이 정의할 수 있다.

$$
p\left(x_{i}\right)=\sum_{j=1}^{k} \tau_{j} p_{j}\left(x_{i} \mid \theta_{j}\right), \tau_{j} \geq 0, \sum_{j=1}^{k} \tau_{j}=1,
$$

여기서 $\tau_{j}$ 는 $\mathrm{k}$ 개의 확률 밀도 함수 중 $\mathrm{j}$ 번째 확률 밀도 함 수가 선택될 확률이다. 이때 최대화하려는 로그 우도 함수 (log-likelihood function)는 식(4)와 같다.

\section{Step 1. Robust spectral envelop estimation}

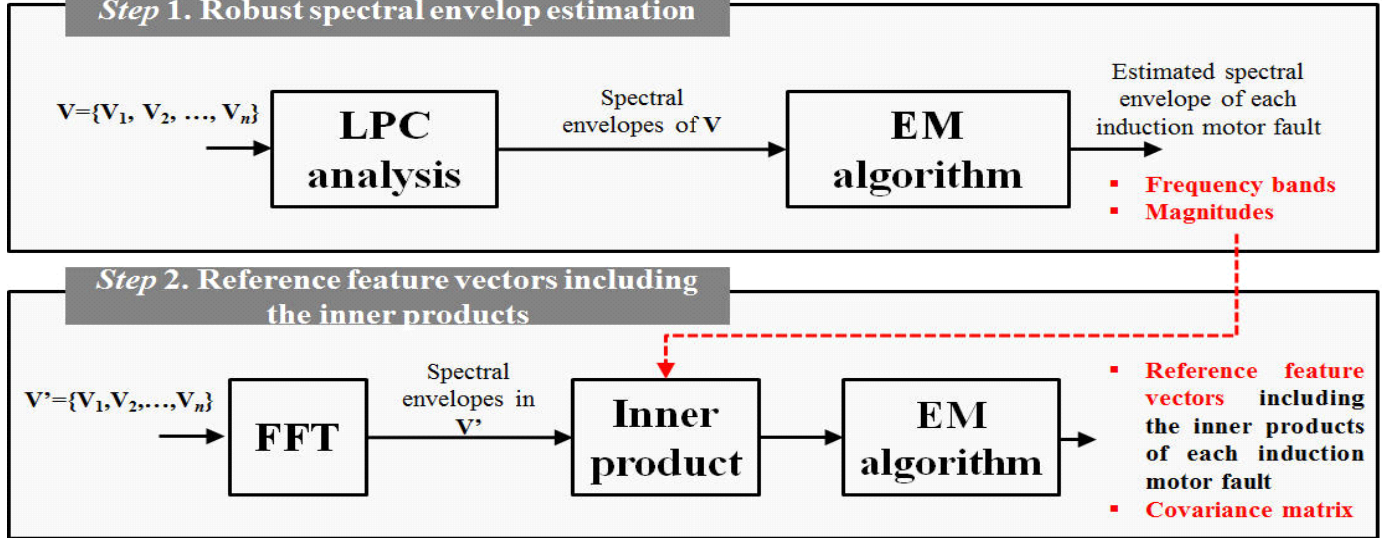

그림 2. 다중 유도전동기 고장을 위한 참조 특징 벡터 생성

Fig. 2. Generation of reference signature vectors for multiple induction motor faults 


$$
\begin{aligned}
& L_{\log }\left(\theta_{1}, \ldots, \theta_{k} ; \tau_{1}, \ldots, \tau_{k} \mid x\right) \\
& \quad=\sum_{i=1}^{n} \sum_{j=1}^{k} c_{i j}\left[\log \left(\left(\tau_{j} p_{j}\left(x_{i} \mid \theta_{j}\right)\right)\right)\right],
\end{aligned}
$$

여기서 최대 우도 추정(maximum likelihood estimation) 에 의해 식 (3)을 최대화 하는 클러스터 파라미터 $\Theta=\left\{\theta_{1}, \theta_{2}, \ldots, \theta_{j}\right\}$ 를 구한다. 이때 $x_{i}$ 는불완전 데이터로 $c_{i j}$ 를 알 수 없으므로 $c_{i j}$ 의 기댓값을 이용하여 식(4)를 최대화한다. $\mathrm{EM}$ 알고리즘은 $\mathrm{E}$ (expectation) 단계와 $\mathrm{M}$ (maximization) 단계의 두 가지 과정으로 나뉘는데, $\mathrm{E}$ 단계에서는 주어진 데이터 $x_{i}$ 와 모델 파라미터 $\Theta=\left\{\theta_{1}, \theta_{2}, \ldots, \theta_{j}\right\}$ 에 대해 $c_{i j}$ 의 기댓값 $\overline{c_{i j}}=E\left[c_{i j} \mid x_{i}, \theta_{1}, \theta_{2}, \ldots, \theta_{j}\right]$ 를 계산한다. 다음으로 $\mathrm{M}$ 단계에서 는 $\mathrm{E}$ 단계에서 구한 기댓값을 이용하여 식(4)의 값을 최대화한다.

\section{3.마할라노비스 거리}

마할라노비스 거리는 변수가 2 개 이상의 수많은 인자에 대 한 집단 사이에 분류를 측정하는 것으로 각 변수 사이에 각 집단의 평균, 공분산을 함께 고려하여 거리를 구하게 되며 식 (5)와 같다[14].

$$
M D_{i}=\sqrt{\left(x-\mu_{i}\right)^{T} C_{i}^{-1}\left(x-\mu_{i}\right)},
$$

여기서 $x$ 는 알려지지 않은 집단을 대표할 수 있는 특징 벡 터, $\mu_{i}$ 는 i번째 집단의 특징 벡터에 대한 산술 평균, $C_{i}^{-1}$ 은 $\mathrm{i}$ 번째 집단의 특징 벡터를 이용하여 구한 공분산행렬 $C_{i}$ 의 역행렬, 그리고 마지막으로 $M D_{i}$ 는 알려지지 않은 집단을 대 표할 수 있는 특징 벡터 $x$ 와 i번째 집단에 대한 마할라노비스 거리를 각각 나타낸다. 일반적으로 $\mathrm{i}$ 번째 집단에 속한 특징 벡터 $x$ 에 대한 $M D_{i}$ 는 0 2정도로 그 값의 크기가 작으므 로, 본 논문에서는 각 결함 유형 사이의 마할라노비스 거리가 최소가 되는 결함 유형을 선택함으로써 유도 전동기 다중 결 함 분류가 가능하다.

\section{4. 유도 전동기 결함 유형별 참조 특징 벡터 생성}

그림 2 는 유도 전동기의 결함 유형별 참조 특징 벡터 추출 을 위한 과정으로 크게 두 단계로 나뉜다.

- 단계 1 에서는 유도 전동기 결함 유형별 특징 주파수를 포 함한 주파수 대역과 그에 상응하는 크기 정보를 추정하며, 이를 결함 유형별 특징 추출에 활용한다. 2장에서 언급하 였듯본 논문에서는 결함 유형별 1 초 길이의 105 개 진동 신호를 취득하였는데, 이 가운데 각 결함 유형별 무작위
로 30 개의 진동 신호를 선택하여 훈련 데이터로 사용한 다. 먼저 각 결함별 30 개의 진동 신호에 대한 스펙트럼 포락선을 나타내기 위해 LPC 계수를 구하고, 이에 대한 주파수 응답 결과를 $\mathrm{EM}$ 알고리즘의 입력으로 사용한다. 즉 동일한 결함에 대한 스펙트럼 포락선일지라도 유도 전 동기의 상태 변화에 따라 그 모양이 미미하게 변하는데, 본 논문에서는 $\mathrm{EM}$ 알고리즘을 적용함으로써 관측된 스 펙트럼 포락선을 바탕으로 추후 발생할 기댓값이 가장 큰 스펙트럼 포락선을 얻을 수 있다. 이는 결과적으로 시간 이 지남에 따라 유도 전동기의 상태 변화, 부하 변동 등으 로 인해 발생할 수 있는 스펙트럼 포락선 변화의 영향을 줄이는 효과를 나타낼 수 있다. 마지막으로 $\mathrm{EM}$ 알고리즘 의 결과를 바탕으로 유도 전동기 결함 유형별 특징 주파 수를 포함한 주파수 대역과 그에 상응하는 크기 정보를 추출한다. 그림 3 은 회전자 불균형 $(\mathrm{RUF})$ 신호를 대상으 로 $\mathrm{LPC}$ 분석 및 $\mathrm{EM}$ 알고리즘을 적용하여 추정한 주파 수 대역과 그 크기 정보를 나타낸다.

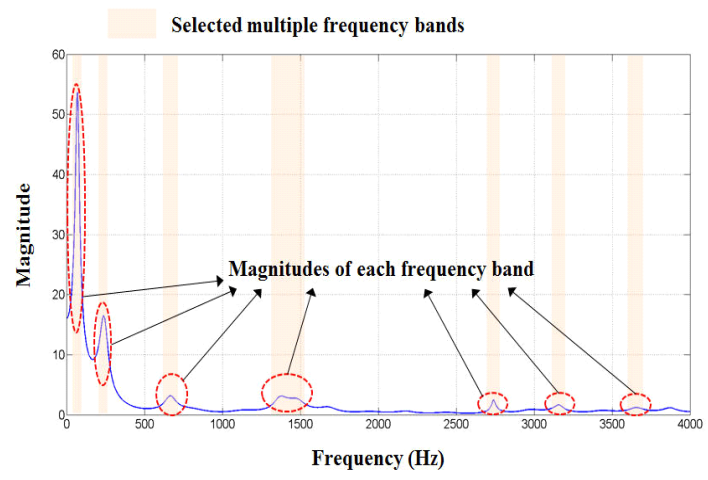

그림 3. LPC와 EM알고리즘을 이용하여 추정한 주파수 대역과 크기 Fig. 3. Selected multiple frequency bands and magnitudes of each frequency using LPC analysis and EM algorithm

- 단계 2에서는 유도 전동기 결함 분류를 위해 사용할 참조 특징 벡터를 추출한다. 먼저 유도 전동기의 결함 유형별 무작위로 선택한 30 개의 진동 신호에 대해 고속 푸리에 변환(fast Fourier transform, FFT)을 이용 스펙트럼 을 각각 구하고, 단계 1 에서 추정한 주파수 대역 및 크기 정보를 이용하여 유도 전동기 각 결함 유형별 내적(inner product)을 구한다. 마지막으로 각 결함 유형별로 구해 진 내적은 $\mathrm{EM}$ 알고리즘 통해 새롭게 추정되며, 추정된 값은 각 결함 유형을 대표하는 참조 특징 벡터로 사용된 다. 또한 마할라노비스 거리 계산을 위해 $\mathrm{EM}$ 알고리즘 


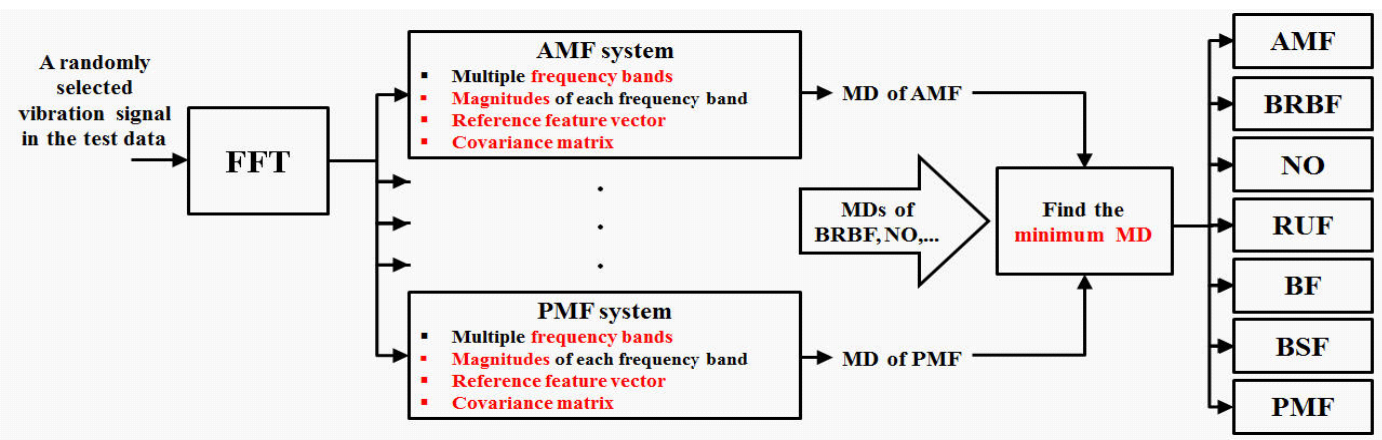

그림 4. 다중 유도전동기 결함 검출을 위한 제안하는 고장 분류 구조

Fig. 4. The proposed fault classification scheme for identifying multiple induction motor faults

표 2. 회전자 불균형(RUF) 진동신호를 사용하였을 때 시스템의 마할라노비스 거리 값

Table 2. Mahalanobis distance using the reference feature vector of the RUF

\begin{tabular}{c|c|c|c|c|c|c|c}
\hline \hline \multirow{2}{*}{$\begin{array}{c}\text { Sample } \\
\text { number }\end{array}$} & \multicolumn{7}{|c}{ Type of faults } \\
\cline { 2 - 8 } & AMF & BRBF & NO & RUF & BF & BSF & PMF \\
\hline 16 & 17.44 & 34.94 & 14.16 & 4.07 & 274.85 & 197.91 & 135.65 \\
\hline 19 & 17.36 & 35.39 & 14.68 & 5.75 & 274.71 & 198.01 & 135.38 \\
\hline 20 & 15.95 & 36.52 & 15.89 & 5.15 & 276.58 & 195.32 & 138.04 \\
\hline 27 & 16.25 & 36.48 & 14.82 & 4.96 & 275.11 & 198.31 & 135.27 \\
\hline 38 & 17.14 & 35.77 & 14.10 & 4.45 & 275.71 & 197.13 & 136.25 \\
\hline 39 & 16.04 & 36.47 & 15.40 & 5.48 & 275.25 & 195.41 & 135.27 \\
\hline 40 & 16.68 & 36.52 & 15.62 & 4.76 & 274.94 & 195.66 & 134.40 \\
\hline 44 & 17.31 & 34.84 & 14.16 & 3.99 & 274.09 & 196.34 & 136.21 \\
\hline 54 & 17.39 & 36.20 & 14.39 & 4.43 & 274.13 & 196.37 & 137.49 \\
\hline 56 & 18.17 & 35.23 & 14.57 & 4.91 & 273.30 & 198.66 & 137.56 \\
\hline \hline
\end{tabular}

결과를 이용하여 유도 전동기의 각 결함 유형별 공분산행 렬(covariance matrix)을 구한다. 본 논문에서 사용하 는 각 결함 유형별 특징 벡터의 크기는 결함 유형별로 다 를 수 있는데, 이는 특징 주파수를 포함한 스펙트럼 포락 선의 모양이 다르기 때문이다. 본 논문에서는 스펙트럼 포락선에서 피크(peak)의 위치를 결함 유형 분류를 위한 특징 주파수로 간주한다.

\section{5. 유도전동기 결함분류}

그림 4 는 본 논문에서 유도 전동기 결함을 분류하기 위한 처리 과정을 보이며, 각 결함 유형별 1 초 진동 신호 105 개 중 학습 데이터로 사용한 30개의 신호를 제외한 75 개의 신호를 테스트 데이터로 사용한다. 먼저 진동 신호가 결함 분류 시스 템으로 입력되면 FFT를 통해 해당 신호에 대한 스펙트럼을 구한다. 구해진 스펙트럼은 각 결함 유형별 특징 추출 및 마 할라노비스 거리 계산을 위한 시스템의 입력으로 사용되어 다 음과 같은 처리 과정을 거친다.

- 단계 1 : 먼저 3장 4절에서 언급하였듯이 각 시스템은 각 결함 유형별 특징 주파수를 포함한 주파수 대역과 크기
정보를 이용하여 입력된 스펙트럼과의 내적을 구한다.

- 단계 2 : 각 시스템은 유도 전동기 결함 유형별 참조 특징 벡터와 공분산행렬을 가지고 있어 단계 1에서 구한 내적 은 식(5)의 $x$ 로, 참조 특징 벡터는 $\mu$ 로, 그리고 공분산 행렬의 역행렬을 구하여 $C^{-1}$ 로 사용하여 마할라노비스 거리를 각각 구한다.

- 단계 3 : 마지막으로 단계 2에서 구한 마할라노비스 거리 정보를 이용하여 그 거리가 최소가 되는 시스템에 대한 범주로 입력 신호를 분류한다. 표 2 는 회전자 불균형 진 동 신호 10 개를 각 시스템의 입력으로 하였을 때 각 시스 템의 마할라노비스 거리 값을 나타낸다.

\section{IV. 실험 결과}

유도 전동기 다중 결함 분류를 위해 본 논문에서는 결함 유형별 1 초 길이의 105 개 진동 신호를 각각 취득하였다. 이 가운데 30 개를 무작위로 선택하여 참조 특징 벡터 생성을 위 한 훈련 데이터로 사용하고, 나머지 75 개는 테스트 데이터로 
표 3. 백색 가우시안 잡음이 포함되지 않은 환경에서의 분류 정확도

Table 3. Classification accuracy in a noiseless environment

\begin{tabular}{|c|c|c|c|c|c|c|c|c|}
\hline & \multicolumn{8}{|c|}{ Classification accuracy (\%) } \\
\hline & AMF & BRBF & $\mathrm{NO}$ & RUF & $\mathrm{BF}$ & BSF & PMF & Average \\
\hline Proposed & 100 & 100 & 100 & 100 & 100 & 100 & 100 & 100 \\
\hline Algorithm 1 [9] & 79.42 & 72.38 & 46.55 & 78.45 & 96.69 & 98.34 & 93.92 & 80.82 \\
\hline Algorithm 2 [10] & 95.24 & 100 & 90.48 & 90.48 & 100 & 100 & 100 & 96.6 \\
\hline Algorithm 3 (11) & 100 & 90 & 84.67 & 100 & 87.33 & 100 & 100 & 94.57 \\
\hline
\end{tabular}

표 4. 백색 가우시안 잡음이 포함된 환경에서의 분류 정확도 $(\mathrm{SNR}=20 \mathrm{~dB})$

Table 4. Classification accuracy in a noisy environment ( $S N R=20 \mathrm{~dB}$ )

\begin{tabular}{|c|c|c|c|c|c|c|c|c|}
\hline & \multicolumn{8}{|c|}{ Classification accuracy (\%) } \\
\hline & AMF & BRBF & NO & RUF & $\mathrm{BF}$ & BSF & PMF & Average \\
\hline Proposed & 100 & 100 & 100 & 92.86 & 100 & 100 & 100 & 98.98 \\
\hline Algorithm 1 [9] & 76.8 & 71.27 & 40.19 & 70.72 & 94.61 & 98.2 & 93.65 & 77.92 \\
\hline Algorithm 2 (10] & 85.71 & 66.67 & 71.43 & 33.33 & 100 & 100 & 95.24 & 78.91 \\
\hline Algorithm 3 (11) & 99.33 & 84 & 83 & 83.33 & 100 & 78 & 100 & 89.67 \\
\hline
\end{tabular}

표 5. 백색 가우시안 잡음이 포함된 환경에서의 분류 정확도 $(\mathrm{SNR}=15 \mathrm{~dB})$

Table 5. Classification accuracy in a noisy environment (SNR=15dB)

\begin{tabular}{|c|c|c|c|c|c|c|c|c|}
\hline & \multicolumn{8}{|c|}{ Classification accuracy (\%) } \\
\hline & AMF & $\mathrm{BRBF}$ & $\mathrm{NO}$ & RUF & $\mathrm{BF}$ & BSF & PMF & Average \\
\hline Proposed & 100 & 96 & 100 & 91 & 100 & 100 & 99.43 & 98.06 \\
\hline Algorithm 1 (9) & 76.52 & 63.26 & 29.01 & 56.63 & 93.78 & 97.65 & 91.02 & 72.55 \\
\hline Algorithm 2 (10] & 52.38 & 52.38 & 54.17 & 33.33 & 95 & 100 & 76.19 & 66.21 \\
\hline Algorithm 3 [11] & 99.33 & 84 & 64.67 & 74.67 & 99.33 & 78 & 99 & 85.57 \\
\hline
\end{tabular}

사용한다. 제안한 알고리즘의 분류 성능은 식(6)과 같이 분류 정확도를 이용하여 평가한다.

$$
C A^{i}=\frac{C L A S S I F Y^{i_{\text {correctly }}}}{F_{\text {total }}^{i}} \times 100(\%),
$$

여기서 $C A^{i}$ 는 i번째 범주에 속하는 결함에 대한 분류 정확 도, $F_{\text {total }}^{i}$ 은 i번째 범주에 속하는 결함의 수(본 논문에서 $\left.F_{\text {total }}^{i}=75\right), C L A S S I F Y_{\text {correctly }}^{i}$ 는 $\mathrm{i}$ 번째 범주에 속하는 결함이 $\mathrm{i}$ 번째 범주에 해당하는 결함이라고 판단된 결함의 총 수를 각각 의미한다.

또한 실제 산업현장에서 유도 전동기 진동 신호 취득 시 주변 환경에 의해 잡음이 추가될 가능성이 있으며, 이는 궁극 적으로 각 결함 신호의 특징 주파수의 미미한 변화에 기인하 는 하나의 요소가 될 수 있다. 센서를 통해 인가되는 잡음은 일반적으로 백색 가우시안 잡음(white Gaussian noise)로 고려되므로 본 논문에서는 취득한 진동 신호에 신호 대 잡음 비(signal-to-noise ratio, SNR)가 $20 \mathrm{~dB}$ 와 $15 \mathrm{~dB}$ 가 되도 록 인위적으로 백색 가우시안 잡음을 추가하여 실험에 함께 사용한다.

표 3에서 5 는 정상 상태 및 잡음이 인위적으로 추가된 환
경에서 제안한 알고리즘과 기존 알고리즘과의 분류 정확도를 나타낸다. 먼저 표 3에서와 같이 백색 가우시안 잡음이 포함 되지 않은 환경에서는 제안한 알고리즘뿐만 아니라 비교 알고 (6계즘 모두 분류 정확도가 최소 $80 \%$ 에서 최대 $100 \%$ 로 좋은 성능을 보였다. 하지만 표 4와 5에서 Algorithm 1의 경우 잡음이 포함된 환경에서 $\mathrm{BRBF}, \mathrm{NO}, \mathrm{RUF}$ 에 대한 분류 정 확도가 $\mathrm{AMF}, \mathrm{BF}, \mathrm{BSF}$ 에 대한 분류 정확도에 비해 다소 낮 은 것을 확인할 수 있는데 이는 그림 5(a)에서 볼 수 있듯이 잡음 환경에서 추출한 zero-crossing 기반 특징이 다른 결함 으로 분류 될 만큼 추출한 특징의 변화가 컸기 때문이다(특징 이 $\mathrm{NO}$ 에서 $\mathrm{BRBF}$ 로, $\mathrm{NO}$ 에서 $\mathrm{RUF}$ 로 이동). 이는 Algorithm 1의 결함 분류 정확도가 약 $81 \%$ 에서 약 $73 \%$ 로 줄어드는 결과를 낳는 결정적인 요인이라고 볼 수 있다. Algorithm 1과 유사하게 Algorithm 2 또한 추가된 잡음 성 분에 의해 그림 $5(\mathrm{~b})$ 에서와 같이 $\mathrm{NO}$ 에서 $\mathrm{RUF}$ 로, $\mathrm{NO}$ 에서 $\mathrm{BRBF}$ 로 통계적 특징(shape indicator와 kurtosis)의 이 동이 발생하였으며 이는 Algorithm 2의 분류 정확도가 약 $97 \%$ 에서 약 $66 \%$ 로 줄어드는데 많은 영향을 미친다. Algorithm 3의 경우 zero-crossing 기반 특징을 이용하는 Algorithm 1과 통계적 특징을 이용하는 Algorithm 2에 비 해 잡음 환경에서 다소 강인한 분류 정확도를 보이나 제안한 

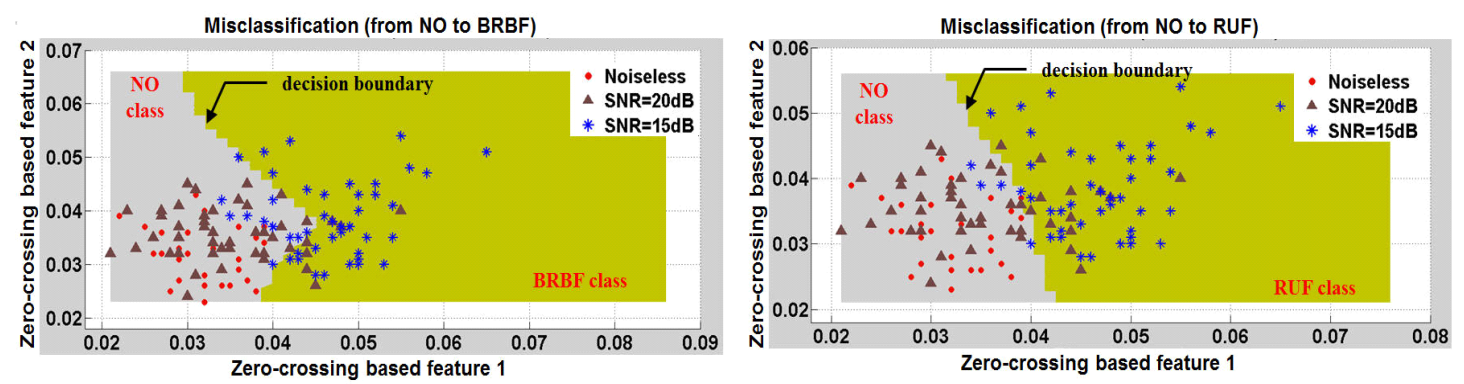

(a)
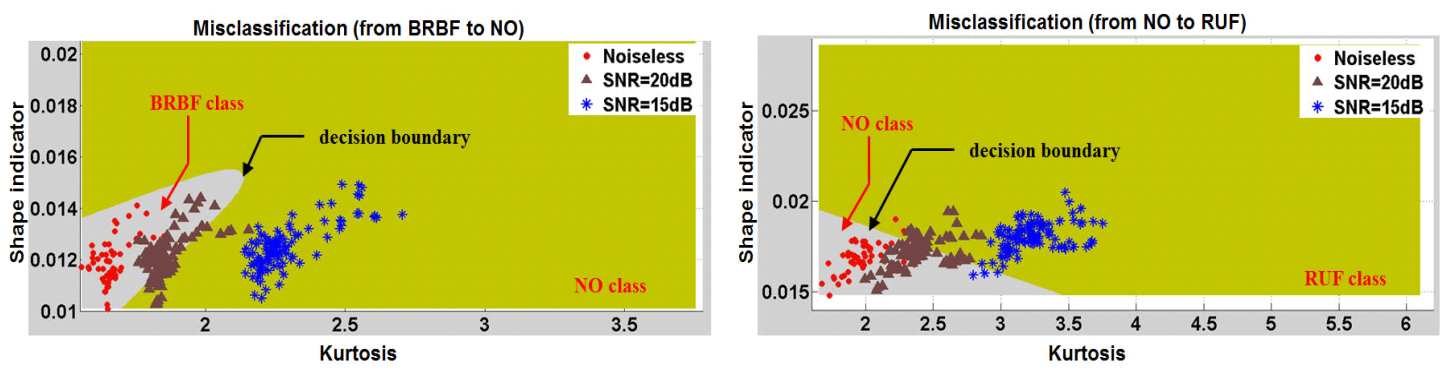

(b)

그림 5. (a) Zero-crossing 기반 특징을 이용하는 Algorithm 1(9)의 특징 변화, (b) 통계적 특징(shape indicator와 kurtosis)를 이용하는 Algorithm 2(10)의 특징 변화

Fig. 5. (a) Feature variation of Algorithm 1(9) using zero-crossing based features, (b) feature variation of Algorithm 2(10) using statistical features (i.e., shape indicator and kurtosis)

알고리즘에 비해서는 분류 성능이 다소 떨어지는 것을 확인할 수 있다. 제안한 알고리즘의 경우 LPC 분석 기법 및 $\mathrm{EM}$ 알 고리즘을 이용한 강인한 스펙트럼 포락선을 구하여 결함 분류 에 사용함으로써 잡음 환경에서도 각 결함 유형별 마할라노비 스 거리 값에 변화가 거의 발생하지 않아 좋은 분류 성능을 보였다. 반면 Algorithm 3의 경우 1차원 진동 신호를 2차원 그레이 영상으로 변환하고 변환된 영상에 물체의 크기 변환, 회전 등에 강인함을 갖는 지역적 특성 벡터들의 집합으로 변 환하는 기법인 SIFT(scale invariant feature transform) 을 적용하여 유도 전동기 각 결함 유형별 특징으로 키포인트 기술자(keypoint descriptor)를 추출하였다. 제안한 알고리 즘과 유사하게 훈련 데이터로부터 추출한 키포인트 기술자를 참조 데이터로 사용하고 알려지지 않은 입력 신호로부터 키포 인트 기술자를 추출하여 두 키포인트 기술자 사이의 유클리디 안 거리(Euclidean distance)의 최솟값을 찾는 방법으로 결 함을 분류하였다. Algorithm 3의 경우 잡음 환경에서 분류 성능이 다소 떨어지는 이유는 1 차원 진동 신호를 2 차원 영상 신호로 직접적으로 변환함으로써 영상 정보에 많은 변화가 생 겼고 이는 그림 6 에서와 같이 키포인트 기술자의 큰 변화를 야기하는 결과를 낳았기 때문이다.

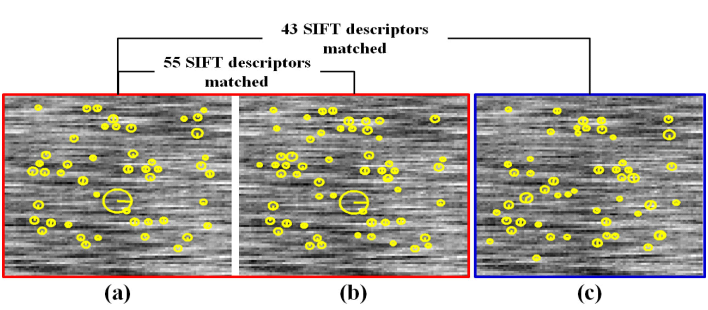

그림 6. SIFT 키포인트의 변화

(a) 잡음이 없는 환경 (b) 잡음이 있는 환경 $(\mathrm{SNR}=20 \mathrm{~dB})$ (c) 잡음이 있는 환경 $(\mathrm{SNR}=15 \mathrm{~dB})$

Fig. 6. Variation of SIFT keypoint descriptors in (a) a noiseless environment, (b) a noisy environment $(\mathrm{SNR}=20 \mathrm{~dB})$, and $(\mathrm{c})$ a noisy environment $(\mathrm{SNR}=15 \mathrm{~dB})$

\section{V. 결 론}

본 논문에서는 유도 전동기의 동작 상태 변화 및 부하 변 동으로 인해 유도 전동기 결함 유형별 특징 주파수를 포함한 스펙트럼 포락선의 변화로 인한 분류 성능 감소를 줄이기 위 해 LPC 분석 기법 및 $\mathrm{EM}$ 알고리즘을 이용하여 강인한 스펙 트럼 포락선을 추정하고, 이를 바탕으로 마할라노비스 거리를 
이용하여 결함을 분류하였다. 제안한 알고리즘의 성능 평가를 위해 진동 신호를 이용한 유도 전동기 결함 검출 알고리즘과 분류 정확도 측면에서 성능을 평가한 결과 제안한 알고리즘의 분류 정확도가 $100 \%$ 로 분류 성능이 $80.82 \%, 96.6 \%$, 94.57\%인 Algorithm 1[9], Algorithm 2[10], Algorithm 3[11]보다 좋은 결과를 보였다. 또한 실제 진동 신호를 취득하는 환경에서 잡음이 포함될 수 있는 가능성을 고려하여 취득한 진동 신호에 백색 가우시안 잡음을 인위적으 로 추가하여 성능을 평가하였다. 실험 결과 제안한 알고리즘 이 잡음이 포함된 환경에서도 $98.98 \%(\mathrm{SNR}=20 \mathrm{~dB})$ 와 $98.06 \%(\mathrm{SNR}=15 \mathrm{~dB})$ 의 분류 정확도를 보여 비교 알고리 즘 대비 최소 $9.36 \%$ 에서 최대 $31.85 \%$ 의 분류 정확도의 향 상을 보였다.

\section{참고문헌}

〔1] Caesarendra, W., Park, J. H., Kosasih, P. B. and Choi, B. K.,"Condition Monitoring of Low Speed Slewing Bearings Based on Ensemble Empirical Mode Decomposition Method," Transactions of the Korean Society for Noise and Vibration Engineering, Vol. 23, No. 2, pp. 131 143, 2013.

[2] Hwang, C.-H., Kim, Y,-M., Kim, C.-H. and Kim, J.-M., "Fault Detection and Diagnosis of Induction Motors using LPC and DTW Methods," Journal of the Korea Society of Computer and Information, Vol. 16, No. 3, pp. 141-147, 2011.

[3] Hwang, C.-H., Kang, M. and Kim, J.-M., "A Study on Robust Feature Vector Extraction for Fault Detection and Classification of Induction Motor in Noise Circumstance," Journal of the Korea Society of Computer and Information, Vol. 16, No. 12, pp. 187-196, 2011.

[4] Nguyen, H. and Kim, J.-M., "An Effective Feature Extraction Method for Fault Diagnosis of Induction Motors," Journal of the Korea Society of Computer and Information, Vol. 18, No. 7, pp. 23-35, 2013.

[5] McInerny, S. A. and Dai, Y., "Basic Vibration Signal Processing for Bearing Fault Detection," IEEE Transactions on Education, Vol. 46, No. 1, pp. 149 156, 2003.

[6] Li, F., Meng, G., Ye, L. and Chen, P., "Wavelet Transform-based Higher-order Statistics for Fault Diagnosis in Rolling Element Bearings," Journal of Vibration and Control, Vol. 14, No. 11, pp. 1691 1709, 2008.

[7] Widodo, A., Yang, B.-S. and Han, T., "Combination of Independent Component Analysis and Support Vector Machines for Intelligent Faults Diagnosis of Induction Motors," Expert Systems with Application, Vol. 32, No. 2, pp. 299 312, 2007.

[8] Prieto, M. D., Cirrincione, G., Espinosa, A. G., Ortega, J. A. and Henao, H., "Bearing Fault Detection by a Novel Condition-Monitoring Scheme Based on Statistical-Time Features and Neural Networks," IEEE Transactions on Industrial Electronics, Vol. 30, No. 8, pp. 3398 3407, 2013.

[9] William, P. E. and Hoffman, M. W., "Identification of Bearing Faults Using Time Domain Zero-Crossings," Mechanical Systems and Signal Processing, Vol. 25, No. 8, pp. 3078 3088, 2011.

〔10] Lei, Y., He, Z. and Zi, Y., "Application of an Intelligent Classification Method to Mechanical Fault Diagnosis," Expert Systems with Applications, Vol. 36, No. 6, pp. 9941-9948, 2009.

〔11〕 Do, V. T. and Chong, U.-P., "Signal Model-Based Fault Detection and Diagnosis for Induction Motors Using Features of Vibration Signal in Two-Dimension Domain," Journal of Mechanical Engineering, Vol. 57. No. 9, pp. 655 666, 2011.

〔12] Han, H. S., Cho, S. and Chong, U.-P., "Neural-Network-based Fault Detection and Diagnosis Method Using EIV(errors-in variables)," Transactions of the Korean Society for Noise and Vibration Engineering, Vol. 21, No. 11, pp. 1020 1028, 2011.

〔13] Yu, J., "Fault Detection Using Principal 
Components-Based Gaussian Mixture Model for Semiconductor Manufacturing Processes," IEEE Transactions on Semiconductor Manufacturing, Vol. 24, No. 3, pp. 432 444, 2011.

〔14] Xiang, S., Nie, F. and Zhang, C., "Learning a Mahalanobis Distance Metric for Data Clustering and Classification," Pattern Recognition, Vol. 41, pp. 3600 3612, 2008.

\section{저 자 소 개}

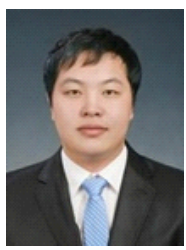

강 명 수

2010: 울산대학교

컴퓨터정보통신공학부 공학석사.

현 재: 울산대학교

전기전자컴퓨터공학과 박사과정.

관심분야: 신호처리, 컴퓨터구조, 병렬처리.

Email : ilmareboy@gmail.com

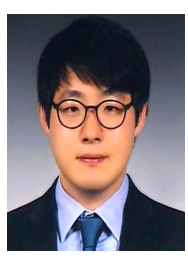

장 원 철

2013: 울산대학교 컴퓨터정보통신공학부 공학사.

현 재: 울산대학교

전기전자컴퓨터공학과 석사과정. 관심분야: 고장진단, 임베디드시스템.

Email : nasha0339@gmail.com

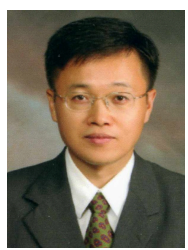

김 종 면

1995: 명지대학교 전기공학과 공학사.

2000: University of Florida 전기컴퓨터공학과 공학석사.

2005: Georgia Tech 전기컴퓨터공학과 공학박사 현 재: 울산대학교 전기공학부 교수 관심분야: 임베디드 $\mathrm{SoC}$, 병렬처리. Email : jmkim07@ulsan.ac.kr 